\title{
Phytocytokines function as immunological modulators of plant immunity
}

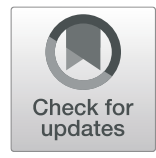

Shuguo $\mathrm{Hou}^{1 \dagger}$, Derui $\mathrm{Liu}^{2+}$ and Ping He $\mathrm{2}^{*}$

\begin{abstract}
Plant plasma membrane-resident immune receptors regulate plant immunity by recognizing microbe-associated molecular patterns (MAMPs), damage-associated molecular patterns (DAMPs), and phytocytokines. Phytocytokines are plant endogenous peptides, which are usually produced in the cytosol and released into the apoplast when plant encounters pathogen infections. Phytocytokines regulate plant immunity through activating an overlapping signaling pathway with MAMPs/DAMPs with some unique features. Here, we highlight the current understanding of phytocytokine production, perception and functions in plant immunity, and discuss how plants and pathogens manipulate phytocytokine signaling for their own benefits during the plant-pathogen warfare.
\end{abstract}

Keywords: Phytocytokine, Damage-associated molecular pattern (DAMP), Pattern-recognition receptor (PRR), pattern-triggered immunity (PTI), Plant immunity

\section{Introduction}

In the early 1990s, systemin was identified as the first peptide signaling molecule in tomato (Pearce et al. 1991). Over the past three decades, dozens of small peptides belonging to different families have been identified and functionally characterized as signaling molecules in various plant species, especially in reference plants Arabidopsis thaliana. Substantial evidence indicates that these peptides, similar to conventional phytohormones, are highly active at a low concentration and play critical roles in the regulation of plant development, reproduction, immunity, and adaptation to environmental stresses. However, different from classic phytohormones which are biosynthesized through specialized metabolic reactions and have conserved structures and functions across the plant kingdom, these peptides are gene products with high sequence diversity and functional specificity across plant species (Matsubayashi 2014; Olsson et al. 2019; Takahashi et al. 2019).

\footnotetext{
* Correspondence: pinghe@tamu.edu

tShuguo Hou and Derui Liu contributed equally to this work.

2Department of Biochemistry \& Biophysics, Texas A\&M University, College

Station, TX 77843, USA

Full list of author information is available at the end of the article
}

In recent years, different types of small secreted peptides have been implicated in regulating plant immunity. Genes encoding many of these immunomodulatory peptides are rapidly and substantially induced during pathogen infections or treatments with pathogen/microbeassociated molecular patterns (PAMPs/MAMPs) (Li et al. 2016a). Recognition of MAMPs by plant plasma membrane (PM)-resident pattern recognition receptors (PRRs) initiates plant pattern-triggered immunity (PTI), the first line of inducible defense against infections (Couto and Zipfel 2016; Yu et al. 2017; Zhou and Zhang 2020). Plant PRRs also recognize host-derived damageassociated molecular patterns (DAMPs), such as extracellular nucleotides, fragments of plant cell wall-derived polysaccharides and immune-related proteins and peptides, which are usually released upon cell damages (Gust et al. 2017; Hou et al. 2019a; Tanaka and Heil 2021). Although immunomodulatory peptides were regarded as a type of DAMPs, most immunological peptides are secreted into extracellular apoplasts in the absence or before cell damages. Furthermore, immunological peptides have different chemical characteristics, maturation processes, and mode-of-actions compared to the conventional DAMPs. These immunological peptides are functionally analogous to animal 
cytokines, a group of signaling peptides produced by immune cells, endothelial cells, and fibroblasts, functioning in health and disease, especially in host immunity, inflammation, trauma, sepsis, and cancer as immunomodulating agents (Banchereau et al. 2012; Luo 2012). Therefore, plant cytokines or phytocytokines were coined to refer to plant peptide hormones that regulate both plant immunity and development as signals of cellcell communication (Luo 2012). Hence, plant-derived immunogenic factors were further divided into two categories with one class as classical DAMPs: molecules that are passively released upon cell damage, and one class as phytocytokines: immunomodulatory peptides that are processed and/or secreted upon infections (Gust et al. 2017; Tanaka and Heil 2021).

Notably, some peptide hormones initially identified as regulators of plant development, reproduction or abiotic stress response have been shown to be involved in plant immunity. Similarly, some immunological peptides also play roles in other physiological processes. Thus, those immunological phytocytokines have dual roles in plant immunity, development, growth, reproduction or stress adaptation, similar to cytokines in animal physiology. Interestingly, some phytocytokine-like sequences were identified in microbes, which could activate or attenuate plant immunity. In this review, we will highlight the recent advances on the mechanisms of phytocytokinemediated plant immunity and discuss how plants and phytopathogens manipulate phytocytokine signaling for the survival of each site during the host-pathogen interactions.

\section{Classification, identification and function of phytocytokines}

The phytocytokines can be divided into two major classes based on whether their precursor proteins contain a signal peptide (Matsubayashi 2014). Systemin, plant elicitor peptide (PEP1), Z. mays immune signaling peptide 1 (ZIP1), and soybean GmPEPs belong to the group of phytocytokines whose precursors are absent of a signal peptide and are classified as non-secreted peptides. Other phytocytokines, including hydroxyproline-rich systemins (HypSys), PAMP-induced secreted peptide 1 (PIP1)/PIP2, serine-rich endogenous peptide 12 (SCOOP12), phytosulfokines (PSKs), plant peptide containing sulphated tyrosine 1 (PSY1), inflorescence deficient in abscission (IDA)/IDA-LIKE 6 (IDL6), root meristem growth factors (RGFs)/GOLVENs (GLVs), and rapid alkalization factors (RALFs) constitute the other group whose precursors harbor a signal peptide and are classified as secreted peptides (Table 1).

Systemin is an 18-amino acid (aa) peptide, identified from wounded tomato leaf extracts and named as it can mediate long-distance systemic defense responses
(McGurl et al. 1992; Pearce et al. 1991). Systemin was found in most species of the Solanaceae family (Ryan and Pearce 2003). Treatment of tomatoes with systemin triggers an array of resistance responses, including the production of proteinase inhibitors, the induction of extracellular alkalization and ethylene emission, and defense against insect herbivory (Zhang et al. 2020a). PEP1, a 23-aa peptide, is the first phytocytokine identified in Arabidopsis. Arabidopsis genome encodes eight PEPs, and their orthologs have been identified in a wide array of plant species, including maize, rice, potato, and soybean (Huffaker et al. 2011; Huffaker et al. 2006; Poretsky et al. 2020). AtPEP1 activates the hallmark of PTI responses, promotes plant resistance to various pathogens, including bacterium Pseudomonas syringae, fungus Botrytis cinerea and oomycete Phytophthora infestans (Huffaker et al. 2006; Yamaguchi et al. 2010; Liu et al. 2013). ZIP1 is a 17-aa peptide isolated from apoplastic fluids of salicylic acid (SA)-pretreated leaves in maize. ZIP1 treatment strongly elicits SA accumulation, induces highly overlapping transcriptional changes associated with SA-responsive genes, and increases maize resistance against the biotrophic fungus Ustilago maydis but susceptibility toward the necrotrophic fungus $B$. cinerea (Ziemann et al. 2018). GmPEP914 and GmPEP890 are two homologous eight-aa peptides isolated from leaf extracts of soybean and identified as alkalization factors of suspension-cultured cells (Yamaguchi et al. 2011). Both peptides can induce the expression of defense genes involved in pathogen defense.

HypSys are a group of homologous hydroxyprolinerich glycopeptides identified in Solanaceae and Convolvulaceae family plants (Chen et al. 2008; NarvaezVasquez et al. 2005; Pearce et al. 2001a). HypSys have similar sizes and functions with those of systemin but do not share sequence homology with systemin. PIP1 and PIP2 peptides are corresponding to the C-termini of two secreted peptide precursor proteins, prePIP1 and prePIP2, identified as MAMP-induced gene products (Hou et al. 2014). Arabidopsis harbors 11 prePIP paralogs, and prePIP orthologs have been found in a large number of monocot and eudicot species. PIP1 and PIP2 are able to activate classical PTI responses and enhance Arabidopsis resistance to $P$. syringae pv. tomato (Pst) DC3000 and Fusarium oxysporum (Hou et al. 2014). Like PIP1 and PIP2, SCOOP12 is derived from the C-terminus of a pathogen-responsive secreted peptide precursor, PROSCOOP12 (Gully et al. 2019). At least 23 PROSCOOPs have been identified in Arabidopsis (Hou et al. 2021a; Rhodes et al. 2021). PROSCOOP orthologs are only found in Brassicaceae family plants. Most SCOOP peptides trigger various PTI responses or/and resistance to Pst DC3000 (Gully et al. 2019; Hou et al. 2021a; Rhodes et al. 2021; Yu et al. 2020). Arabidopsis plants defective 
Table 1 Classification, perception and functions of phytocytokines

\begin{tabular}{|c|c|c|c|c|}
\hline Type & Phytocytokines & Receptor & Functions & Reference \\
\hline \multirow[t]{4}{*}{$\begin{array}{l}\text { Non- } \\
\text { secreted } \\
\text { peptides }\end{array}$} & Systemin & SYR1 & $\begin{array}{l}\text { Induction of proteinase inhibitors, extracellular } \\
\text { alkalization, and ethylene emission, mediation of } \\
\text { systemic defense response, defense against insect } \\
\text { herbivory }\end{array}$ & $\begin{array}{l}\text { Pearce et al. 1991; Ryan and Pearce 2003; Wang et al. } \\
2018\end{array}$ \\
\hline & $\begin{array}{l}\text { Pep1, Pep2, } \\
\text { Pep3 }\end{array}$ & $\begin{array}{l}\text { PEPR1, } \\
\text { PEPR2 }\end{array}$ & $\begin{array}{l}\text { Activation of PTI responses, and plant resistance to } B \text {. } \\
\text { cinerea, } P \text {. syringae, and } P \text {. irregular, activation of ET, } \\
J A \text {, and SA signaling pathways, mediation of systemic } \\
\text { immunity }\end{array}$ & $\begin{array}{l}\text { Huffaker et al. 2006, 2011; Liu et al. 2013; Ross et al. } \\
\text { 2014; Yamaguchi et al. 2006, } 2010\end{array}$ \\
\hline & $\mathrm{ZIP1}$ & Unknown & $\begin{array}{l}\text { Activation of SA defense signaling, maize resistance } \\
\text { against } U \text {. maydis and susceptibility to } B \text {. cinerea }\end{array}$ & Ziemann et al. 2018 \\
\hline & $\begin{array}{l}\text { GmPep914, } \\
\text { GmPep890 }\end{array}$ & Unknown & $\begin{array}{l}\text { Induction of extracellular alkalization and the } \\
\text { expression of defense genes }\end{array}$ & Yamaguchi et al. 2011 \\
\hline \multirow{12}{*}{$\begin{array}{l}\text { Secreted } \\
\text { peptides }\end{array}$} & PSK & PSKR1 & \multirow{2}{*}{$\begin{array}{l}\text { Attenuation of PTI and SA signaling, activation of JA } \\
\text { signaling, increase resistance to necrotrophic } \\
\text { pathogens and susceptibility to biotrophic } \\
\text { pathogens }\end{array}$} & \multirow{2}{*}{$\begin{array}{l}\text { Amano et al. 2007; Igarashi et al. 2012; Matsubayashi } \\
\text { et al. 2002; Matsubayashi and Sakagami 1996; Mosher } \\
\text { et al. 2013; Rodiuc et al. 2016; Zhang et al. } 2018\end{array}$} \\
\hline & PSY1 & PSY1R? & & \\
\hline & PIP1, PIP2 & RLK7 & $\begin{array}{l}\text { Activation of PTI responses and plant resistance to } P \text {. } \\
\text { syringae and } F \text {. oxysporum }\end{array}$ & Hou et al. 2014 \\
\hline & IDA & $\begin{array}{l}\text { HAE, } \\
\text { HSL2 }\end{array}$ & Regulation of plant resistance to $P$. syringae & \multirow[t]{2}{*}{$\begin{array}{l}\text { Butenko et al. 2003; Patharkar and Walker 2016; } \\
\text { Stenvik et al. 2008; Wang et al. } 2017\end{array}$} \\
\hline & IDL6 & $\begin{array}{l}\text { HAE, } \\
\text { HSL2 }\end{array}$ & $\begin{array}{l}\text { Suppression of PTI responses and SA signaling, } \\
\text { attenuation plant resistance to } P \text {. syringae }\end{array}$ & \\
\hline & SCOOP12 & MIK2 & $\begin{array}{l}\text { Activation of PTI responses, plant resistance to } P \text {. } \\
\text { syringae and } F \text {. oxysporum, and susceptible to } E \text {. } \\
\text { amylovora }\end{array}$ & $\begin{array}{l}\text { Gully et al. 2019; Hou et al. 2021a, b; Rhodes et al. } \\
2021\end{array}$ \\
\hline & RGF7/GLV4 & $\mathrm{RGI} / 3 / 4$ & Activation of PTI responses & \multirow{2}{*}{$\begin{array}{l}\text { Matsuzaki et al. 2010; Ou et al. 2016; Stegmann et al. } \\
\text { 2021; Wang et al. 2021; Whitford et al. } 2012\end{array}$} \\
\hline & RGF9/GLV2 & RGI3 & $\begin{array}{l}\text { Activation of PTI responses } \\
\text { Promotion of FLS2 accumulation }\end{array}$ & \\
\hline & HypSys & Unknown & $\begin{array}{l}\text { Induction of proteinase inhibitors, extracellular } \\
\text { alkalization, and ethylene emission, activation of } \\
\text { resistance to insect herbivory }\end{array}$ & Pearce et al. 2001a, b; Pearce and Ryan, 2003 \\
\hline & RALF1 & FER-LLG & Attenuation of PTI, activation of JA signaling & \multirow{3}{*}{$\begin{array}{l}\text { Haruta et al. 2014; Li et al. 2015; Stegmann et al. } \\
\text { 2017; Guo et al. } 2018\end{array}$} \\
\hline & RALF17 & Unknown & Activation of PTI responses & \\
\hline & RALF22, RALF23 & FER-LLG & Attenuation of PTI signaling & \\
\hline
\end{tabular}

in SCOOP12 are more resistant to Erwinia amylovora (Gully et al. 2019). Similar to HypSys, PIPs and SCOOPs, IDA is a serine and glycine-rich peptide. It was initially identified as a key regulator of floral organ abscission in Arabidopsis (Butenko et al. 2003). IDA homologs are conserved in a wide range of plant species (Butenko et al. 2003). The IDA family comprises eight members in Arabidopsis (Vie et al. 2015). Of these, IDA and IDL6 have been reported to be involved in plant immunity. IDA regulates plant resistance likely through the control of premature leaf abscission (Patharkar and Walker, 2016). IDL6 promotes Arabidopsis susceptibility to Pst DC3000 (Wang et al. 2017).

PSKs are five-aa peptides with two sulfated tyrosine residues. They were initially identified as a plant growthpromoting factor and have been found to regulate multiple processes of plant growth, development, and stress responses (Matsubayashi and Sakagami 1996; Sauter 2015; Yang et al. 2001). PSKs are universally distributed in the plant kingdom. In Arabidopsis, PSK signaling attenuates PTI responses, compromises plant resistance to the hemibiotrophic Pst DC3000 and the oomycete Hyaloperonospora arabidopsidis, but enhances resistance against the necrotrophic fungal pathogen Alternaria brassicicola (Igarashi et al. 2012; Mosher et al. 2013; Rodiuc et al. 2016). In tomato, PSK enhances the resistance to necrotrophic fungal pathogen $B$. cinerea (Zhang et al. 2018). Arabidopsis PSY1 is an 18-aa glycopeptide with a sulfated tyrosine residue. It was originally identified as a functional analogy to PSKs in stimulating plant cellular proliferation and expansion (Amano et al. 2007). PSY homologs have been identified in diverse plant species, including rice, banana, tomato, and wheat (Pruitt et al. 2017). Like PSKs, PSY1 signaling likely suppresses PTI responses, promotes Arabidopsis resistance to $A$. brassicicola but susceptibility to Pst DC3000 and F. oxysporum (Mosher et al. 2013; Shen and Diener 2013). RGF family peptides also known as GLV peptides 
represent another group of tyrosine-sulfated peptides that were initially identified as key regulators of root meristem maintenance and gravitropism in Arabidopsis (Matsuzaki et al. 2010; Whitford et al. 2012). The RGF peptide family comprises 11 members in Arabidopsis (Matsuzaki et al. 2010). Among them, RGF7/GLV4 and RGF9/GLV2, which are transcriptionally regulated in plants upon infection by $P$. syringae, contribute to the activation of immune responses and the increase of resistance to P. syringae (Stegmann et al. 2021; Wang et al. 2021).

RALFs, a group of 5-kilodalton $(\mathrm{kDa})$ polypeptides originally extracted from tobacco leaves, induces rapid alkalization of extracellular compartment and functions in root growth and development (Pearce et al. 2001b). Different from other linear peptides, RALFs have four conserved cysteines which form two disulfide bonds that are vital to the peptide activity. RALFs are widely present in various tissues and organs of different plant species (Pearce et al. 2001b). Arabidopsis genome encodes more than 30 RALFs, and some of them have been shown to play a positive or negative role in plant immunity (Blackburn et al. 2020) (Table 1).

\section{Phytocytokines are perceived by cell surface receptors}

A major common feature of cytokines and phytocytokines is that they are perceived by specific cell surface receptors. Receptors for cytokines are structurally diverse and mainly divided into five major superfamilies: type I (hematopoietin family) and type II (interferon family) cytokine receptors, tumor necrosis factor (TNF) family receptors, immunoglobulin superfamily receptors, receptor tyrosine kinases, and chemokine receptors (Wang et al. 2009). In contrast, phytocytokines are usually perceived by cell surface-resident receptor-like kinases (RLKs), which contain an extracellular domain, a transmembrane region, and a cytoplasmic kinase domain resembling the animal receptor tyrosine kinases (Couto and Zipfel 2016; Escocard de Azevedo Manhaes et al. 2021; Shiu and Bleecker 2001) (Table 1). Plant RLKs are classified into different subfamilies based on their extracellular domains. Leucine-rich repeat-RLKs (LRR-RLKs) with extracellular LRRs constitute the largest subfamily of RLKs and function as receptors of some immunological phytocytokines. Of these, tomato SYSTEMIN RECEPTOR 1 (SYR1) and SYR2 perceive systemin (Wang et al. 2018), Arabidopsis PEP1 RECEPTOR 1 (PEPR1)/ PEPR2 recognize PEPs (Yamaguchi et al. 2006), Arabidopsis RECEPTOR-LIKE 7 (RLK7) recognizes PIP1 and PIP2 (Hou et al. 2014), Arabidopsis MALE DISCOVERER 1-INTERACTING RECEPTOR-LIKE KINASE 2 (MIK2) recognizes SCOOPs (Hou et al. 2021a; Rhodes et al. 2021), HAESA and HAESA-LIKE2 (HSL2) recognize IDA (Santiago et al. 2016), RGF1 INSENSITIVE 3 (RGI3) itself or together with RGI4 recognizes RGF7 and RGF9/GLV2 (Stegmann et al. 2021; Wang et al. 2021), PSK RECEPTOR 1 (PSKR1) recognizes PSKs (Matsubayashi et al. 2002; Wang et al. 2015), and PSY1R likely recognizes PSY1 (Amano et al. 2007). These phytocytokine receptors all belong to LRR X and LRR XI clades of LRR-RLKs, which are phylogenetically close to the LRR XII subfamily of LRR-RLKs, including some of the well-studied receptors of proteinaceous MAMPs, such as the bacterial flagellin receptor FLAGELLIN SENSING 2 (FLS2) and ELONGATION FACTOR-Tu RECEPTOR (EFR). This suggests a close evolutionary relationship between the phytocytokine- and MAMPtriggered immunity. Upon phytocytokine perception, the LRR-RLK receptors often heterodimerize with SOMATIC EMBRYOGENESIS RECEPTOR-LIKE KINASE (SERK) LRR-RLKs, e.g., BRASSINOSTEROID INSENSITIVE 1 (BRI1)-ASSOCIATED RECEPTOR KINASE 1 (BAK1)/SERK3 and SERK4 (Liu et al. 2020b; Ma et al. 2016).

Catharanthus roseus receptor-like kinase 1-like (CrRLK1L) proteins with two extracellular malectin-like domains play important roles in plant development, such as polarized growth, cell elongation, cell wall integrity sensing, and hormonal responses (Franck et al. 2018; Li et al. 2016b; Zhu et al. 2021). Recent studies suggest a critical role of CrRLK1Ls in plant immunity as receptors of RALFs. Arabidopsis CrRLK1L FERONIA (FER) functions as the receptor of different RALFs, including RALF1 and RALF23 (Haruta et al. 2014; Stegmann et al. 2017) (Table 1). Interestingly, RALF23/RALF33 negatively, whereas RALF17 positively regulates PRRmediated immunity in a FER-dependent manner (Stegmann et al. 2017). Structural and biochemical results indicate that RALF23 induces a complex formation between FER and LORELEI (LRE)-LIKE GLYCOSYLPHOSPHATIDYLINOSITOL (GPI)-ANCHORED PROTEIN 1 (LLG1) or LLG2 to assemble a RALF23-LLG1/ 2-FER ternary complex (Xiao et al. 2019). Although LLGs were initially proposed as coreceptors of FER, they could directly bind to RALFs without FER. It appears that RALF23 is initially recognized by LLGs, resulting in the recruitment of FER to the heteromeric complex (Xiao et al. 2019). Thus, LLGs might be the bona fide RALF receptors whereas CrRLK1Ls act as the coreceptors to strengthen the interaction.

\section{Regulation of phytocytokine expression}

Regulating the expression of phytocytokine precursors is one of the early immune responses ( $\mathrm{Li}$ et al. 2016a). Accordingly, some phytocytokines are identified as they are upregulated by MAMP treatments or pathogen infections. For example, prePIP1 and prePIP2, the precursors 
of PIP1 and PIP2, were identified through the analysis of MAMP-regulated gene transcription (Hou et al. 2014). The expression of prePIP1 and prePIP2 is swiftly upregulated $30 \mathrm{~min}$ post-treatment with bacterial MAMP flg22 or elf18 and reaches a peak about one-hour posttreatment. Likewise, the expression of prePIP1 is also highly induced by chitin, a MAMP from fungi, suggesting that prePIP1 may play a conserved role in plant resistance to diverse pathogens. Consistently, the expression of prePIPlin leaves and in roots is induced by the bacterial Pst DC3000 and the fungal $F$. oxysporum $\mathrm{f}$. sp. conglutinans strain 699 (Foc 699), respectively, and PIP1 promotes plant resistance to both Pst DC3000 and Foc 699 (Hou et al. 2014). PROSCOOP12 was identified as it is highly induced by infections of diverse pathogens, including B. cinerea, Pst DC3000, and E. amylovora (Gully et al. 2019); preRGF7 was induced by Pst DC3000 infection at transcriptional and post-transcriptional levels (Wang et al. 2021). Two PROPEP1 paralogs, PROPEP2 and PROPEP3 are highly induced by MAMPs or pathogens, including Pst DC3000, B. cinerea, and $P$. infestans (Huffaker et al. 2006); the precursors of PSK and PSY1, proPSKs and proPSY1, were upregulated during the infection of B. cinerea or A. brassicicola in Arabidopsis and tomato (Igarashi et al. 2012; Mosher et al. 2013; Zhang et al. 2018). Consistent with the upregulation of phytocytokine genes, the expression of their receptors is also upregulated by MAMPs in some cases. For instance, MAMP treatment or pathogen infection induce the expression of PEPR1, PEPR2, RLK7, MIK2, HAESA, and PSKR1 (Kemmerling et al. 2011; Lewis et al. 2015). Interestingly, some phytocytokine precursor genes are transcriptionally downregulated by pathogen infections. For instance, the expression of preRGF9/GLV2 is suppressed in leaves upon infection with P. syringae pv. maculicola and Pst DC3000 (Stegmann et al. 2021). It remains to be determined how down-regulation of preRGF9/GLV2 plays a positive role in plant immunity.

MAMP-induced phytocytokine genes may further upscale the expression of their precursor genes, thus amplifying the phytocytokine signaling through a positive feedback loop. For example, Pep1, PIP1, SCOOP12, and RGF7 are able to induce the expression of their precursor genes, respectively (Gully et al. 2019; Hou et al. 2014; Huffaker et al. 2006; Wang et al. 2021). Inducible overexpression of preRGF7 in plants leads to the activation of MPK3 and MPK6, and the activated MPK3 and MPK6 in turn upregulate preRGF7 expression via the downstream WRKY33 transcription factor, suggesting a self-amplification loop in the regulation of preRGF7 expression (Wang et al. 2021). The discovery of MIK2 as the SCOOP receptor is enlightened by this positive feedback regulation. Activation of MIK2 kinase in a RLK7-
MIK2 chimeric receptor (extracellular domain of RLK7 fused with transmembrane and intracellular domains of MIK2) upon PIP1 treatment induced the expression of some PROSCOOP genes, which were consequently confirmed to be the ligands of MIK2 (Hou et al. 2021a). In addition, some phytocytokines may not only induce the expression of their own precursor genes but also precursor genes of other phytocytokines. For instance, PIP1 and Pep1 can upregulate the expression of each other's precursor genes (Hou et al. 2014), indicating a signaling network regulated by different phytocytokines.

\section{Regulation of phytocytokine maturation and release}

As mentioned above, phytocytokines are usually derived from precursor proteins with the following characteristics: an amino (N)-terminal signal peptide (only for secreted peptides), a carboxyl (C)-terminal region conserved in the same family of peptides, and a variable region (also named prodomain) between signal peptide and conserved region (Fig. 1) (Matsubayashi 2014; Olsson et al. 2019). Once translated, the phytocytokine precursors enter the secretory pathway with the guide of signal peptide and are finally secreted into the extracellular compartment (apoplast) of plant cells as biologically active, mature phytocytokines. In the secretory pathway of endoplasmic reticulum (ER) and Golgi or the apoplast, proteolytic cleavages of signal peptide and prodomain, and post-translational modifications, such as tyrosine sulfation, proline hydroxylation, hydroxyproline arabinosylation, and intramolecular disulfide bond formation, are required for the phytocytokine maturation (Matsubayashi 2014; Olsson et al. 2019). For the phytocytokine precursors without a signal peptide (non-secreted peptides), they do not enter the canonical ERGolgi secretory pathway and undergo post-translational modifications and are proposed to be released into the extracellular compartment via an unconventional secretory pathway or during cellular damage (Ding et al. 2012). The processing of the phytocytokine precursors to remove their prodomains that happens in the cytosol or the apoplast is also essential for their maturation (Fig. $1)$.

Substantial studies demonstrate that the maturation and secretion/release of phytocytokines are promoted by pathogen infections or other environmental stresses (Hou et al. 2021b). PROPEP1, the precursor protein of PEP1, lacks a canonical N-terminal signal sequence and is tethered on the cytosolic side of the tonoplasts. Arabidopsis METACASPASE 4 (MC4) and the other type-II metacaspases (MC5 to MC9) are required for PEP1 cleavage from PROPEP1 after an arginine residue (R69) (Hander et al. 2019; Shen et al. 2019). Plant metacaspases are structurally homologous to animal caspases 


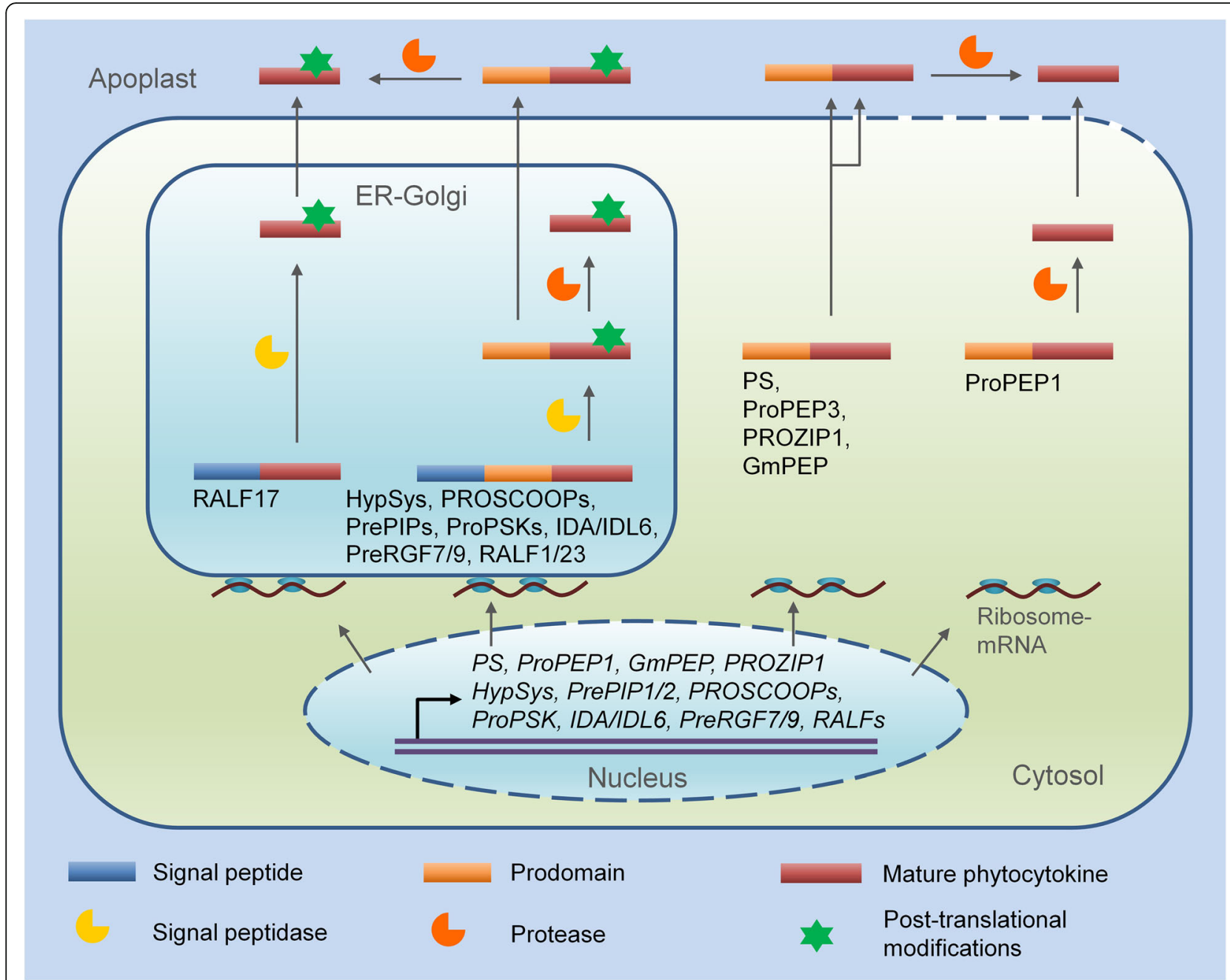

Fig. 1 A model of phytocytokine maturation and release. After translation, phytocytokine precursors with signal peptide enter into the ER-Golgi secretory pathway, where they undergo post-translational modifications and proteolytic cleavages to remove signal peptide and prodomain, and then are secreted into the apoplast. Phytocytokine precursors without signal peptide enter into the cytosol, where they are maturely processed to remove prodomains. This group of phytocytokines are released into the apoplast likely through unconventional secretion or disrupted plasma membrane. The maturation processing of phytocytokine may also happen in the apoplast

(Hou et al. 2018). Arabidopsis MC4 is activated when cytosolic $\mathrm{Ca}^{2+}$ concentration reaches a threshold during cell membrane disruption or the MAMP flagellin peptide flg22-triggered $\mathrm{Ca}^{2+}$ elevation in cytosol (Hander et al. 2019; Shen et al. 2019). Recent structural studies revealed the molecular basis of $\mathrm{Ca}^{2+}$-dependent $\mathrm{MC4}$ activation and PROPEP1 processing (Zhu et al. 2020). In addition, infection with either virulent or avirulent bacterial pathogens, salt stress treatment, and cell wall damage (CWD) also induce PROPEP3 cleavage to PEP3 (Engelsdorf et al. 2018; Yamada et al. 2016). It is unclear whether the elevation of cytosolic $\mathrm{Ca}^{2+}$ and $\mathrm{MC}$ activation are responsible for the induced PROPEP3 cleavage. Cell membrane damage might be a cause of PEP release, but it's puzzling how PEP is released during PTI and salt stress when no observable cell membrane disruption is involved.

Tomato systemin is processed from the C-terminus of a precursor protein, prosystemin (PS) by two tomato subtilases, SLPHYTASPASE 1 (SlPhyt1) and SlPhyt2, at two aspartate residues (Beloshistov et al. 2018). Subtilases are a family of subtilisin-like serine proteases (Hou et al. 2018). SlPhyt-mediated cleavage produces a modified systemin with an extra leucine residue at the $\mathrm{N}$ terminus (Leu-systemin), which is further processed by a leucine aminopeptidase to generate mature systemin (Beloshistov et al. 2018). PSKs are also maturely processed from their precursor proPSKs after an aspartate residue by SlPhyt2 in tomato. The PSK processing in tomato abscission region is induced by drought stress 
(Reichardt et al. 2020). However, proPSK1 and proPSK4 are processed by subtilases SBT1.1 and SBT3.8 respectively in Arabidopsis (Srivastava et al. 2008; Stuhrwohldt et al. 2021). The cleavage of IDA precursor proteins is executed by SBT4.12, SBT4.13, and SBT5.2 (Schardon et al. 2016).

Some RALFs, including RALF1, RALF22, and RALF23, contain a signal peptide and a RRXL cleavage site in the junction region between prodomain and the mature RALF peptides, which is cleaved by the ER-localized subtilase SITE-1 PROTEASE (S1P) (Srivastava et al. 2009; Stegmann et al. 2017). Treatment with elf18, an epitope peptide of MAMP elongation factor Tu (EF-Tu), or inoculation with Pst DC3000 hrcC mutant, which is deficient in the bacterial type III secretion system, significantly promotes the processing of the PRORALF23 (Stegmann et al. 2017). This cleavage leads to the activation and secretion of RALF peptides as active phytocytokines. The RALFs without the RRXL cleavage site, such as RALF17, are not cleaved by S1P (Stegmann et al. 2017). ZIP1 is processed from PROZIP1 by maize papain-like cysteine protease (PLCP) CP1 and CP2 (Ziemann et al. 2018). The processing of ZIP1 is promoted by SA, an immune-related phytohormone that is usually highly induced in plants upon attacks of biotrophic and hemibiotrophic pathogens (Ziemann et al. 2018). ZIP1 strongly elicits SA accumulation and activates PLCP in maize leaves, indicating a positive feedback loop in regulating ZIP1 signaling (Ziemann et al. 2018). Like PROPEP1, both PS and PROZIP1 lack canonical signal peptides. Notably, SlPhyts and CPs are apoplastic proteases. Therefore, it is possible that PS and PROZIP1 are released into extracellular spaces during cellular damages or through unconventional protein secretory pathways and then processed to mature systemin and ZIP1 in apoplasts. Other phytocytokines, including HypSys, PIP1, PIP2, and SCOOP12, were also shown to be processed (Hou et al. 2021a; Hou et al. 2014; Pearce et al. 2001a), but the proteases that mediate the cleavage have not been identified yet. Precursors of HypSys, IDA, PIP1, PIP2, and SCOOP12 contain typical signal peptide, and are supposed to be secreted into apoplasts. It remains unknown whether the cleavage of these precursors occurs in the cytoplasm or apoplasts to become the mature phytocytokines.

HypSys contains -PPSPX- motifs, which have been identified as a repeating unit in hydroxyproline-rich glycoproteins, a major class of cell wall structural proteins (Narvaez-Vasquez et al. 2005; Pearce et al. 2001a). Interestingly, some SCOOPs, such as SCOOP2, also carry a -PPSPX- motif (Hou et al. 2021a). It is possible that these phytocytokines are associated with and released from cell walls, an interesting question to be explored in the future.

\section{Phytocytokines trigger overlapping and unique signaling pathways with MAMPs}

Upon perception by cognate PRRs, MAMPs trigger convergent PTI responses, including phosphorylation of the receptor-like cytoplasmic kinases (RLCKs), the elevation of cytosolic $\mathrm{Ca}^{2+}$ concentration, transient apoplastic ROS burst, the activation of mitogen-activated protein kinases (MAPKs) and calcium-dependent protein kinases (CDPKs), reprogramming of defense gene expression, callose deposition, production of immune-related hormones and antimicrobial components, and plant growth inhibition (DeFalco and Zipfel, 2021; Yu et al. 2017; Zhou and Zhang 2020). Like MAMPs, some phytocytokines also activate canonical PTI responses (Fig. 2). For example, Pep1, PIP1, and SCOOP12 all trigger MAPK activation, ROS production, callose deposition, and induce the expression of some PTI marker genes (Gully et al. 2019; Hou et al. 2021a; Hou et al. 2014; Ranf et al. 2011; Rhodes et al. 2021). Since the expression of these phytocytokines and cognate receptors are induced by MAMPs, these phytocytokines were thought to amplify MAMP responses. In agreement with this, some flg22induced responses or resistance to pathogens are partially compromised when these phytocytokine signaling pathways are disrupted (Gravino et al. 2017; Hou et al. 2014; Rhodes et al. 2021; Tintor et al. 2013). It is worth noting that SCOOP-MIK2 signaling promotes flg22- but antagonizes Pep1-induced ROS production (Rhodes et al. 2021), that complicates the crosstalk between MAMP- and phytocytokine-mediated immune signaling.

Moreover, the type and intensity of immune responses induced by phytocytokines could be different from that of MAMPs. The immune induction also differs between different phytocytokines, which may contribute to the diversification and specificity of plant immunity. For example, Pep1 and SCOOP12, like flg22, induce RLCK BOTRYTIS-INDUCED KINASE 1 (BIK1) phosphorylation and activate BIK1-depdendent immune responses, whereas PIP1 seems to induce immune responses through a BIK1-independent manner (Hou et al. 2021a; Hou et al. 2014; Liu et al. 2013; Tintor et al. 2013). In addition, Pep1 and SCOOP12 induce a strong immune response in roots but a weak response in leaves compared to flg22 (Hou et al. 2021a; Poncini et al. 2017). SCOOPs are able to cause root browning, a phenotype likely related to cell wall modifications and root immunity, which was not reported for flg22 or Pep1 (Felix et al. 1999; Hou et al. 2021a; Huffaker et al. 2006). Pep1 also activates distinct gene networks from flg22 in different cell types of roots (Rich-Griffin et al. 2020).

The plant defense hormones SA, ethylene (ET)/jasmonic acid (JA) function antagonistically in plants against biotrophic and necrotrophic pathogens, and all three hormones play an intertwined role in regulating flg22/ 


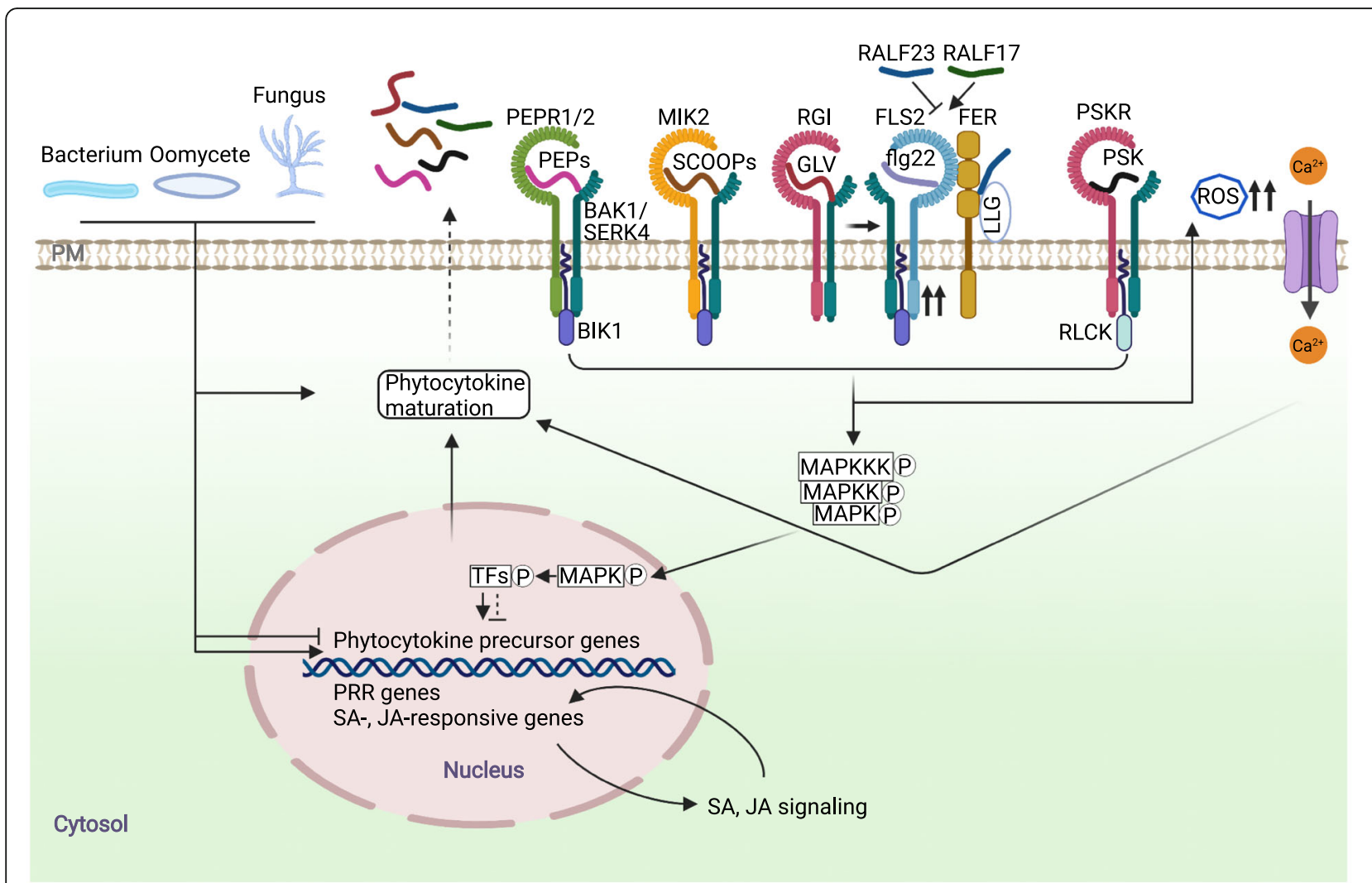

Fig. 2 A proposed model of phytocytokine-mediated regulation of plant immunity. Pathogen infections swiftly activate or inhibit the expression of phytocytokine precursor genes, or promote phytocytokine maturation. When released to the apoplast, phytocytokines are perceived by their corresponding receptor- and co-receptors. These perceptions activate ROS burst, $\mathrm{Ca}^{2+}$ influx, and phosphorylation of MAP kinase kinase kinases (MAPKKKS) mediated by BIK1 and/or related RLCKs. $\mathrm{Ca}^{2+}$ may promote phytocytokine maturation. Activated MAPKs may phosphorylate transcription factors (TFs), which further up- or down-regulate the expression of phytocytokine precursor genes and PRR genes, and SA- and/or JA-responsive genes, thus amplifying or attenuating immunity. Phytocytokine signaling may also modulate PRR complex stability and assembly. For example, the complex formation between FLS2 and RGI induced by flg22 increases FLS2 abundance, and the association between FER, FLS2, and BAK1 is promoted or inhibited by RALF17 or RALF23, thus positively or negatively regulates PTI, respectively. Due to limited space, only several of well-studied phytocytokines and their receptors are shown in this Figure

elf18-triggered PTI (Kim et al. 2014). The specificity of phytocytokine-regulated immune signaling is also correlated with these immune-related hormones. For example, PIP1 and ZIP1 have been shown to activate SA signaling pathway and contribute to biotrophic pathogens (Hou et al. 2019b; Ziemann et al. 2018). In contrast, PSK, PSY1, and RALF activate JA signaling pathway to enhance plant resistance to necrotrophic pathogens and/ or compromise plant resistance to hemibiotrophic pathogens (Guo et al. 2018; Mosher et al. 2013). Interestingly, Pep1 is able to activate both SA and ET/JA signaling pathways and promote plant resistance to both biotrophic and necrotrophic pathogens (Liu et al. 2013; Ross et al. 2014; Tintor et al. 2013; Yamaguchi et al. 2010). In addition, some phytocytokines also regulate plant immunity by crosstalking with some other hormone signaling pathways. For examples, PSK initiates auxin-dependent resistance to $B$. cinerea in tomato (Zhang et al. 2018), RALF suppresses ABA signaling although the role of this suppression in plant immunity remains to be explored (Chen et al. 2016; Yu et al. 2012).

\section{Phytocytokine signaling modulates PRR complex stability and assembly}

The plasma membrane-resident receptors of both phytocytokines and MAMPs and their shared BAK1/SERK4 coreceptors provide a platform for the intertwined regulations between phytocytokine and MAMP receptors (Fig. 2). Phytocytokines and cognate receptors are able to modulate MAMP receptor complex assembly and signaling. FER forms a complex with EFR/FLS2 and BAK1, and promotes elf18/flg22-induced complex assembly between EFR/FLS2 and BAK1 in such strengthening PTI signaling (Stegmann et al. 2017). RALF23 perception by FER suppresses the ligand-induced EFR/FLS2-BAK1 complex formation (Stegmann et al. 2017). RALF23 may negatively regulate FER function in salt tolerance by 
inducing its internalization (Zhao et al. 2018), raising a possibility that RALF23 dampens the PTI signaling likely through a similar mechanism. Interestingly, RALF17, distinct from REALF23, promotes elf18-triggered ROS production via FER (Stegmann et al. 2017). It is possible that RALF17 strengthens the FER-mediated complex assembly between EFR and BAK1 by competing with RALF23 for FER binding. However, the mechanism underlying the RALF23 and RALF17 opposite modulation of the PRR complex-mediated signaling remains unclear. Additionally, FER closest homologs, ANXUR1 (ANX1) and ANX2 also associate with FLS2 and BAK1 (Mang et al. 2017). Likewise, flg22 perception by FLS2 promotes ANX1 association with BAK1. However, ANX1 negatively regulates flg22-induced FLS2-BAK1 complex formation and plant PTI responses (Mang et al. 2017). It would be interesting to test in the future if FER and ANX1 compete with each other for their association with the FLS2-BAK1 complex to either enhance or dampen PTI responses and if this FER-ANX balance is under the control of different RALF peptides. RGI3 forms an flg22-induced complex with FLS2, suggesting RGI3 is part of the activated PRR signaling platform (Stegmann et al. 2021). Interestingly, RGF9/GLV2 perception by RGI receptors increases FLS2 abundance and thus promotes FLS2 signaling output (Fig. 2) (Stegmann et al. 2021). It will be interesting to investigate the potential relationship between FLS2 abundance and RGI3FLS2 association. FLS2 abundance is regulated by two E3 ligases plant U-box protein 12 (PUB12) and PUB13mediated ubiquitination ( $\mathrm{Lu}$ et al. 2011), raising the possibility that RGI3 interferes PUB12/PUB13-mediated ubiquitination of FLS2.

\section{Modulation of plant immunity by pathogen- encoded phytocytokine mimicry}

Although phytocytokines are considered as plant-specific signaling molecules, some phytocytokine homologs or phytocytokine-like sequences are found in microbes, especially in plant pathogenic fungi, bacteria, and parasitic nematodes. Like phytocytokines in plants, most of microbial phytocytokine-like sequences are derived from C-termini of precursor proteins with an $\mathrm{N}$-terminal signal peptide. These pathogen-encoded phytocytokine-like sequences are recognized by the same receptors and activate similar pathways with the corresponding phytocytokines in plants, and they are considered as phytocytokine mimics (Ronald and Joe 2018). The microbial phytocytokine mimics usually function as virulence factors to promote pathogen pathogenicity by hijacking phytocytokine-mediated cellular processes. However, some of these phytocytokine-like motifs are recently found to be capable of activating plant immune responses and are presumed to be potential MAMPs (Hou et al. 2021a; Rhodes et al. 2021).

Rice Xanthomonas resistance 21 (XA21), an LRRRLK-type PRR, recognizes a synthetic 21-aa peptide with a sulfated tyrosine residue derived from the $\mathrm{C}$-terminus of $\operatorname{RaxX}(\operatorname{RaxX} 21-\mathrm{sY})$ from the bacterial pathogen $X$. oryzae pv. oryzae (Xoo) strain PXO99, and activates immune responses for a broad-spectrum resistance to Xoo (Pruitt et al. 2015; Song et al. 1995). Xanthomonas strain lacking $\operatorname{raxX}$ is impaired in its ability to infect rice lacking XA21, suggesting that $\operatorname{RaxX}$ is a virulence factor. RaxX is a small protein with a predicted N-terminal signal peptide, which is highly conserved in many Xanthomonas species (Pruitt et al. 2015). Sequence analysis indicated that RaxX21 is similar to the phytocytokine PSY1 (Amano et al. 2007; Pruitt et al. 2017; Pruitt et al. 2015). Like PSY1, RaxX21-sY peptides from diverse Xanthomonas species promote plant root elongation, suggesting that RaxX21-sY is a functional mimic of plant PSYs. It was hypothesized that RaxX21-sY targets the plant cell surface-localized receptor of PSYs to elevate plant susceptibility to Xanthomonas strains. Although, PSY1R has been suggested to be a potential receptor of PSY1 in Arabidopsis (Amano et al. 2007), psy1r mutants are still responsive to both PSYs and RaxX21-sY (Pruitt et al. 2017), suggesting that an additional receptor(s) may be involved. Unlike RaxX21-sY, PSY peptides do not activate XA21-mediated immunity (Pruitt et al. 2017). This suggests that XA21 is a lately evolved receptor to specifically recognize RaxX21-sY and trigger plant resistance to RaxX-harboring pathogens.

Sequence alignments indicate that RALF homologs are not only widely distributed in plants but also across phylogenetically distant phytopathogens, such as pathogenic Fusarium fungi and Actinobacteria (Masachis et al. 2016; Thynne et al. 2017; Wood et al. 2020). The RALF-like proteins are also present in multiple species of root-knot nematodes (Masachis et al. 2016; Thynne et al. 2017; Zhang et al. 2020b). These microbial RALF homologs exhibit highly similar sequence characteristics with plant RALFs, including an N-terminal signal peptide and four highly conserved cysteine residues (Masachis et al. 2016; Thynne et al. 2017; Zhang et al. 2020b). Some pathogen RALF-like peptides have been shown to mimic plant RALFs and modulate FER-mediated responses, favoring the infection process of pathogens. For instance, the root-infecting fungus $F$. oxysporum secretes a functional RALF mimic (F-RALF) to induce extracellular alkalization by directly targeting FER to favor the fungal multiplication (Masachis et al. 2016). Likewise, the root-knot nematode Meloidogyne incognita contains two RALF-like genes (MiRALF1 and MiRALF3), which mimic host RALFs to bind FER, thereby manipulating FER-mediated signaling to promote $M$. incognita 
parasitism (Zhang et al. 2020b). Therefore, FER represents a virulence target of these microbial RALF-like factors. Two FER homologous CrRLK1L LETUM1 (LET1) and LET2 were recently reported to activate the nucleotide-binding domain leucine-rich repeat (NLR)type immune receptor suppressor of $m k k 1 \quad m k k 22$ (SUMM2)-mediated autoimmunity and cell death (Huang et al. 2020; Liu et al. 2020a). RALFs or related molecules could be the potential ligands of LET1/LET2 in regulating SUMM2 activation. It is tempting to speculate that RALFs or other phytocytokine mimics may function as "avirulence" factors to activate NLRmediated immunity.

Although most RALF-like sequences identified in pathogens are close to Arabidopsis RALF1, pathogenencoded RALF mimics intermix with plant RALFs without an apparent evolutionary origin with the phylogenetic analyses (Masachis et al. 2016; Thynne et al. 2017; Zhang et al. 2020b). Notably, RALF-like sequences found in the genomes of the poplar pathogen Sphaerulina musiva and Septoria populicola are close related to a poplar RALF gene (Thynne et al. 2017). These observations implicate pathogens may have acquired $R A L F$ genes by horizontal gene transfer from their host plants.

As an unidentified proteinaceous elicitor(s) isolated from Fusarium strains activates MIK2-mediated PTI responses, a functional analog(s) of SCOOPs is predicted to be encoded by Fusarium genomes (Coleman et al. 2021). Blast-searching with Arabidopsis SCOOPs revealed that some SCOOP-like (SCOOPL) motifs exist in different families of proteins in Fusarium strains (Hou et al. 2021a; Rhodes et al. 2021). However, distinct from classical phytocytokine mimics, all these SCOOPLs seem to be distributed in proteins belonging to different families. For example, one of the Fusarium SCOOPLs localizes in the N-terminus of a putative transcription regulator conserved in Fusarium strains (Hou et al. 2021a); another Fusarium SCOOPL is present in the Cterminus of a DNA topoisomerase (Rhodes et al. 2021). In addition, SCOOPLs also exist in an unknown function protein conserved in bacterial Comamonadaceae (Hou et al. 2021a). Importantly, synthetic peptides corresponding to some of these SCOOPLs in Fusarium and Comamonadaceae are functional in activating MIK2and/or BAK1/SERK4-dependent immune responses, though the activities are weaker than Arabidopsis SCOOPs (Hou et al. 2021a; Rhodes et al. 2021). Knockout of a SCOOPL in F. oxysporum 5176 enhanced the fungal pathogenicity in Arabidopsis (Hou et al. 2021a). Therefore, SCOOPLs may function as MAMPs, rather than virulence factors, to activate MIK2-BAK1/SERK4mediated PTI responses.

Compared to the wide distribution of SCOOPLs in fungal Fusarium spp. and bacterial Comamonadaceae, plant SCOOPs are only present in Brassicaceae plants and are undergoing a significant gene expansion (Gully et al. 2019). This suggests that plant SCOOPs may have evolved later than microbial SCOOPLs. In addition, phylogenetic analysis indicates that peptide motifs of Arabidopsis SCOOPs, Fusarium and Comamonadaceae SCOOPLs might have evolved independently (Hou et al. 2021a). Moreover, plant SCOOPs are derived from small peptide precursor proteins, whereas Fusarium and Comamonadaceae SCOOPLs reside in proteins belonging to distinct families. The divergence of protein families harboring SCOOP/SCOOPL also suggests that SCOOPs and SCOOPLs might have evolved convergently but unlikely by horizontal gene transfers. Thus, it's predicted that plant SCOOPs may have been convergently evolved to mimic microbial SCOOPLs and amplify SCOOPL-triggered immunity (Hou et al. 2021a).

\section{Concluding remarks and perspectives}

Plant endogenous peptide signaling has been discovered to be involved in the regulation of plant immunity for a long time. These immunomodulatory peptides were recently defined as "phytocytokines", a term derived from "cytokines" as a group of peptides functioning in metazoan immune system. Recent progresses have uncovered that phytocytokines, like cytokines, are produced and released into extracellular compartments when plants experience pathogen invasions; phytocytokines, like MAMPs and DAMPs, are recognized by plasma membrane-localized receptors to activate canonical PTI responses or regulate plant immunity through a unique signaling mechanism. However, more phytocytokines and their cognate receptors still await to be identified in plants especially in crops. The functional specificity and coordination between different phytocytokines of intraand interfamily remains largely unknown. Future efforts are needed to decipher how phytocytokines specialize plant resistance to a class of pathogens and how different phytocytokines coordinate to achieve a broadspectrum of plant resistance.

Several phytocytokine-like sequences have been identified in microbes. These microbe-encoded phytocytokinelikes seem to function as virulence factors or MAMPs to dampen or activate plant immunity. Besides, many phytocytokines are perceived by receptors evolutionarily closed to the receptors of some proteinaceous MAMPs. It implies an evolutionary relevance between phytocytokine signaling and MAMP signaling. A systematic and comparative analysis of phytocytokine-likes in microbes at the genome level may shed new light on the evolution of plant immunity. PTI and effector-triggered immunity (ETI), two tiers of plant immune pathways, have been recently shown to potentiate each other (Ngou et al. 2021; Yuan et al. 2021). It will be interesting to 
determine the potential involvement of phytocytokines in plant ETI, and whether phytocytokine signaling could function as a connecting point between plant PTI and ETI. Finally, some immunological phytocytokines also function in developmental processes and plant tolerance to diverse abiotic stresses. The molecular mechanisms underlying signaling crosstalks between phytocytokinemediated different physiological processes need to be investigated. Addressing these questions will advance our understanding of the phytocytokine functions and elucidate how plants integrate different stress responses through phytocytokine signaling.

\begin{abstract}
Abbreviations
ANX1: ANXUR1; BAK1: BRASSINOSTEROID INSENSITIVE 1 (BRI1)-ASSOCIATED RECEPTOR KINASE 1; BIK1: BOTRYTIS-INDUCED KINASE 1; CDPKs: Calciumdependent protein kinases; CrRLK1L: C. roseus receptor-like kinase 1-like: DAMPs: Damage-associated molecular patterns; ETI: Effector-triggered immunity; EFR: ELONGATION FACTOR-Tu RECEPTOR; EF-Tu: Elongation factor Tu; ER: Endoplasmic reticulum; ET: Ethylene; FER: FERONIA; FLS2: FLAGELLIN SENSING 2; IDA: Inflorescence deficient in abscission; IDL6: IDA-LIKE 6; GLVs: GOLVENs; HSL2: HAESA-LIKE 2; HypSys: Hydroxyproline-rich systemins; JA: Jasmonic acid; LET1: LETUM1; LLG1: LORELEI (LRE)-LIKE

GLYCOSYLPHOSPHATIDYLINOSITOL (GPI)-ANCHORED PROTEIN 1; MAPKs: Mitogen-activated protein kinases; MC4: METACASPASE 4; MIK2: MALE DISCOVERER 1-INTERACTING RECEPTOR-LIKE KINASE 2; PAMPS/ MAMPs: Pathogen/microbe-associated molecular patterns; PEP1: Plant elicitor peptide 1; PEPR1: PEP1 RECEPTOR 1; PIP1: PAMP-induced secreted peptide 1; PLCP: Papain-like cysteine protease; PM: Plasma membrane; PRRs: Pattern recognition receptors; PS: Prosystemin; PSKs: Phytosulfokines; PSKR1: PSK RECEPTOR 1; PSY1: Plant peptide containing sulphated tyrosine 1; PTI: Pattern-triggered immunity; RALFs: Rapid alkalization factors; RGFs: Root meristem growth factors; RGI3: RGF1 INSENSITIVE 3; RLCKs: Receptor-like cytoplasmic kinases; RLKs: Receptor-like kinases; RLK7: RECEPTOR-LIKE 7: SA: Salicylic acid; SCOOP12: Serine-rich endogenous peptide 12; SCOOPL: SCOOP-like; SERK: SOMATIC EMBRYOGENESIS RECEPTOR-LIKE KINASE; SIPhyt1: SLPHYTASPASE 1; SUMM2: Suppressor of $m k k 1$ mkk2 2; SYR1: SYSTEMIN RECEPTOR 1; S1P: SITE-1 PROTEASE; XA21: Xanthomonas resistance $21 ; Z I P 1: Z$. mays immune signaling peptide
\end{abstract}

\section{Acknowledgements}

We apologize to those whose work is not cited due to space limitations.

\section{Authors' contributions}

All authors contributed to the writing of the article. The authors read and approved the final manuscript.

\section{Funding}

The work was supported by National Science Foundation (NSF) (IOS1951094) and National Institutes of Health (NIH) (R01GM092893) to P.H., the Natural Science Foundation of Shandong Province (ZR2020MC022) and Youth Innovation Technology Project of Higher School in Shandong Province (2020KJF013) to S.H. The funding agencies have no roles in the design of the study and collection, analysis, and interpretation of data and in writing the manuscript.

\section{Availability of data and materials}

Not applicable.

\section{Declarations}

\section{Competing interests}

Author P.H. is a member of the Editorial Board and was not involved in the journal's review of, or decisions related to, this manuscript.

\section{Author details}

School of Municipal \& Environmental Engineering, Shandong Jianzhu University, Jinan 250100, China. ${ }^{2}$ Department of Biochemistry \& Biophysics, Texas A\&M University, College Station, TX 77843, USA.

Received: 21 June 2021 Accepted: 18 August 2021

Published online: 15 September 2021

\section{References}

Amano Y, Tsubouchi H, Shinohara H, Ogawa M, Matsubayashi Y (2007) Tyrosinesulfated glycopeptide involved in cellular proliferation and expansion in Arabidopsis. Proc Natl Acad Sci U S A 104(46):18333-18338. https://doi.org/1 0.1073/pnas.0706403104

Banchereau J, Pascual V, O'Garra A (2012) From IL-2 to IL-37: the expanding spectrum of anti-inflammatory cytokines. Nat Immunol 13(10):925-931. https://doi.org/10.1038/ni.2406

Beloshistov RE, Dreizler K, Galiullina RA, Tuzhikov Al, Serebryakova MV, Reichardt S, Shaw J, Taliansky ME, Pfannstiel J, Chichkova NV, Stintzi A, Schaller A, Vartapetian AB (2018) Phytaspase-mediated precursor processing and maturation of the wound hormone systemin. New Phytol 218(3):1167-1178. https://doi.org/10.1111/nph.14568

Blackburn MR, Haruta M, Moura DS (2020) Twenty years of progress in physiological and biochemical investigation of RALF peptides. Plant Physiol 182(4):1657-1666. https://doi.org/10.1104/pp.19.01310

Butenko MA, Patterson SE, Grini PE, Stenvik GE, Amundsen SS, Mandal A, Aalen RB (2003) Inflorescence deficient in abscission controls floral organ abscission in Arabidopsis and identifies a novel family of putative ligands in plants. Plant Cell 15(10):2296-2307. https://doi.org/10.1105/tpc.014365

Chen J, Yu F, Liu Y, Du C, Li X, Zhu S, Wang X, Lan W, Rodriguez PL, Liu X, Li D, Chen L, Luan S (2016) FERONIA interacts with ABI2-type phosphatases to facilitate signaling cross-talk between abscisic acid and RALF peptide in Arabidopsis. Proc Natl Acad Sci U S A 113(37):E5519-E5527. https://doi.org/1 0.1073/pnas.1608449113

Chen YC, Siems WF, Pearce G, Ryan CA (2008) Six peptide wound signals derived from a single precursor protein in Ipomoea batatas leaves activate the expression of the defense gene sporamin. J Biol Chem 283(17):11469-11476. https://doi.org/10.1074/jbc.M709002200

Coleman AD, Maroschek J, Raasch L, Takken FLW, Ranf S, Huckelhoven R (2021) The Arabidopsis leucine-rich repeat receptor-like kinase MIK2 is a crucial component of early immune responses to a fungal-derived elicitor. New Phytol 229(6):3453-3466. https://doi.org/10.1111/nph.17122

Couto D, Zipfel C (2016) Regulation of pattern recognition receptor signalling in plants. Nat Rev Immunol 16(9):537-552. https://doi.org/10.1038/nri.2016.77

DeFalco TA, Zipfel C (2021) Molecular mechanisms of early plant patterntriggered immune signaling. Mol Cell S1097-2765(21)00598. https://doi.org/1 0.1016/j.molcel.2021.07.029

Ding Y, Wang J, Wang J, Stierhof YD, Robinson DG, Jiang L (2012) Unconventional protein secretion. Trends Plant Sci 17(10):606-615. https:// doi.org/10.1016/j.tplants.2012.06.004

Engelsdorf T, Gigli-Bisceglia N, Veerabagu M, McKenna JF, Vaahtera L, Augstein F, Van der Does D, Zipfel C, Hamann T (2018) The plant cell wall integrity maintenance and immune signaling systems cooperate to control stress responses in Arabidopsis thaliana. Sci Signal 11(536):eaao3070. https://doi. org/10.1126/scisignal.aao3070

Escocard de Azevedo Manhaes AM, Ortiz-Morea FA, He P, Shan L (2021) Plant plasma membrane-resident receptors: surveillance for infections and coordination for growth and development. J Integr Plant Biol 63(1):79-101. https://doi.org/10.1111/jipb.13051

Felix G, Duran JD, Volko S, Boller T (1999) Plants have a sensitive perception system for the most conserved domain of bacterial flagellin. Plant J 18(3): 265-276. https://doi.org/10.1046/j.1365-313X.1999.00265.x

Franck CM, Westermann J, Boisson-Dernier A (2018) Plant malectin-like receptor kinases: from cell wall integrity to immunity and beyond. Annu Rev Plant Biol 69(1):301-328. https://doi.org/10.1146/annurev-arplant-042817-040557

Gravino M, Locci F, Tundo S, Cervone F, Savatin DV, De Lorenzo G (2017) Immune responses induced by oligogalacturonides are differentially affected by AvrPto and loss of BAK1/BKK1 and PEPR1/PEPR2. Mol Plant Pathol 18(4): 582-595. https://doi.org/10.1111/mpp.12419

Gully K, Pelletier S, Guillou MC, Ferrand M, Aligon S, Pokotylo I, Perrin A, Vergne E, Fagard M, Ruelland E, Grappin P, Bucher E, Renou JP, Aubourg S (2019) The SCOOP12 peptide regulates defense response and root elongation in 
Arabidopsis thaliana. J Exp Bot 70(4):1349-1365. https://doi.org/10.1093/jxb/ ery 454

Guo H, Nolan TM, Song G, Liu S, Xie Z, Chen J, Schnable PS, Walley JW, Yin Y (2018) FERONIA receptor kinase contributes to plant immunity by suppressing jasmonic acid signaling in Arabidopsis thaliana. Curr Biol 28: 3316-3324 e3316.

Gust AA, Pruitt R, Nurnberger T (2017) Sensing danger: key to activating plant immunity. Trends Plant Sci 22(9):779-791. https://doi.org/10.1016/.tplants.2017.07.005

Hander T, Fernández-Fernández ÁD, Kumpf RP, Willems P, Schatowitz H, Rombaut D, Staes A, Nolf J, Pottie R, Yao P, Gonçalves A, Pavie B, Boller T, Gevaert K, Van Breusegem F, Bartels S, Stael S (2019) Damage on plants activates $\mathrm{Ca}^{2+-}$ dependent metacaspases for release of immunomodulatory peptides. Science 363(6433):eaar7486. https://doi.org/10.1126/science.aar7486

Haruta M, Sabat G, Stecker K, Minkoff BB, Sussman MR (2014) A peptide hormone and its receptor protein kinase regulate plant cell expansion. Science 343(6169):408-411. https://doi.org/10.1126/science.1244454

Hou S, Jamieson P, He P (2018) The cloak, dagger, and shield: proteases in plantpathogen interactions. Biochem J 475(15):2491-2509. https://doi.org/10.1042/ BCJ20170781

Hou S, Liu D, Huang S, Luo D, Liu Z, Wang P, Mu R, Han Z, Chai J, Shan L, He P (2021a) Immune elicitation by sensing the conserved signature from phytocytokines and microbes via the Arabidopsis MIK2 receptor. bioRxiv preprint. https://doi.org/10.1101/2021.01.28.428652

Hou S, Liu Z, Shen H, Wu D (2019a) Damage-associated molecular patterntriggered immunity in plants. Front Plant Sci 10:646. https://doi.org/10.3389/ fpls.2019.00646

Hou S, Shen H, Shao H (2019b) PAMP-induced peptide 1 cooperates with salicylic acid to regulate stomatal immunity in Arabidopsis thaliana. Plant Signal Behav 14(11):1666657. https://doi.org/10.1080/15592324.2019.1666657

Hou S, Wang X, Chen D, Yang X, Wang M, Turra D, Di Pietro A, Zhang W (2014) The secreted peptide PIP1 amplifies immunity through receptor-like kinase 7. PLoS Pathog 10(9):e1004331. https://doi.org/10.1371/journal.ppat.1004331

Hou S, Zhang J, He P (2021b) Stress-induced activation of receptor signaling by protease-mediated cleavage. Biochem J 478(10):1847-1852. https://doi.org/1 0.1042/BCJ20200941

Huang Y, Yin C, Liu J, Feng B, Ge D, Kong L, Ortiz-Morea FA, Richter J, Hauser MT, Wang WM, Shan L, He P (2020) A trimeric CrRLK1L-LLG1 complex genetically modulates SUMM2-mediated autoimmunity. Nat Commun 11(1):4859. https://doi.org/10.1038/s41467-020-18600-8

Huffaker A, Dafoe NJ, Schmelz EA (2011) ZmPep1, an ortholog of Arabidopsis elicitor peptide 1 , regulates maize innate immunity and enhances disease resistance. Plant Physiol 155(3):1325-1338. https://doi.org/10.1104/pp.110.1 66710

Huffaker A, Pearce G, Ryan CA (2006) An endogenous peptide signal in Arabidopsis activates components of the innate immune response. Proc Natl Acad Sci U S A 103(26):10098-10103. https://doi.org/10.1073/pnas.06037271 03

Igarashi D, Tsuda K, Katagiri F (2012) The peptide growth factor, phytosulfokine, attenuates pattern-triggered immunity. Plant J 71(2):194-204. https://doi. org/10.1111/j.1365-313X.2012.04950.X

Kemmerling B, Halter T, Mazzotta S, Mosher S, Nurnberger T (2011) A genomewide survey for Arabidopsis leucine-rich repeat receptor kinases implicated in plant immunity. Front Plant Sci 2:88

Kim Y, Tsuda K, Igarashi D, Hillmer RA, Sakakibara H, Myers CL, Katagiri F (2014) Mechanisms underlying robustness and tunability in a plant immune signaling network. Cell Host Microbe 15(1):84-94. https://doi.org/10.1016/j. chom.2013.12.002

Lewis LA, Polanski K, de Torres-Zabala M, Jayaraman S, Bowden L, Moore J, Penfold CA, Jenkins DJ, Hill C, Baxter L, Kulasekaran S et al (2015) Transcriptional dynamics driving MAMP-triggered immunity and pathogen effector-mediated immunosuppression in Arabidopsis leaves following infection with Pseudomonas syringae pv tomato DC3000. Plant Cell 27(11): 3038-3064. https://doi.org/10.1105/tpc.15.00471

Li C, Yeh FL, Cheung AY, Duan Q, Kita D, Liu MC, Maman J, Luu EJ, Wu BW, Gates L, Jalal M, Kwong A, Carpenter H, Wu HM (2015)

Glycosylphosphatidylinositol-anchored proteins as chaperones and coreceptors for FERONIA receptor kinase signaling in Arabidopsis. Elife 4: e06587. https://doi.org/10.7554/eLife.06587

Li B, Meng X, Shan L, He P (2016a) Transcriptional regulation of pattern-triggered immunity in plants. Cell Host Microbe 19(5):641-650. https://doi.org/10.1016/ j.chom.2016.04.011
Li C, Wu HM, Cheung AY (2016b) FERONIA and her pals: functions and mechanisms. Plant Physiol 171(4):2379-2392. https://doi.org/10.1104/pp.16. 00667

Liu J, Huang Y, Kong L, Yu X, Feng B, Liu D, Zhao B, Mendes GC, Yuan P, Ge D, Wang WM, Fontes EPB, Li P, Shan L, He P (2020a) The malectin-like receptorlike kinase LETUM1 modulates NLR protein SUMM2 activation via MEKK2 scaffolding. Nat Plants 6(9):1106-1115. https://doi.org/10.1038/s41477-0200748-6

Liu J, Li J, Shan L (2020b) SERKs. Curr Biol 30(7):R293-R294. https://doi.org/10.101 6/.cub.2020.01.043

Liu Z, Wu Y, Yang F, Zhang Y, Chen S, Xie Q, Tian X, Zhou JM (2013) BIK1 interacts with PEPRs to mediate ethylene-induced immunity. Proc Natl Acad Sci U S A 110(15):6205-6210. https://doi.org/10.1073/pnas.1215543110

Lu D, Lin W, Gao X, Wu S, Cheng C, Avila J, Heese A, Devarenne TP, He P, Shan L (2011) Direct ubiquitination of pattern recognition receptor FLS2 attenuates plant innate immunity. Science 332(6036):1439-1442. https://doi.org/10.1126/ science. 1204903

Luo L (2012) Plant cytokine or phytocytokine. Plant Signal Behav 7(12):1513-1514. https://doi.org/10.4161/psb.22425

Ma X, Xu G, He P, Shan L (2016) SERKing coreceptors for receptors. Trends Plant Sci 21(12):1017-1033. https://doi.org/10.1016/j.tplants.2016.08.014

Mang H, Feng B, Hu Z, Boisson-Dernier A, Franck CM, Meng X, Huang Y, Zhou J, Xu G, Wang T, Shan L, He P (2017) Differential regulation of two-tiered plant immunity and sexual reproduction by ANXUR receptor-like kinases. Plant Cell 29(12):3140-3156. https://doi.org/10.1105/tpc.17.00464

Masachis S, Segorbe D, Turrà D, Leon-Ruiz M, Fürst U, El Ghalid M, Leonard G, López-Berges MS, Richards TA, Felix G, Di Pietro A (2016) A fungal pathogen secretes plant alkalinizing peptides to increase infection. Nat Microbiol 1(6): 16043. https://doi.org/10.1038/nmicrobiol.2016.43

Matsubayashi Y (2014) Posttranslationally modified small-peptide signals in plants. Annu Rev Plant Biol 65(1):385-413. https://doi.org/10.1146/annurev-a rplant-050312-120122

Matsubayashi Y, Ogawa M, Morita A, Sakagami Y (2002) An LRR receptor kinase involved in perception of a peptide plant hormone, phytosulfokine. Science 296(5572):1470-1472. https://doi.org/10.1126/science.1069607

Matsubayashi Y, Sakagami Y (1996) Phytosulfokine, sulfated peptides that induce the proliferation of single mesophyll cells of Asparagus officinalis L. Proc Natl Acad Sci U S A 93(15):7623-7627. https://doi.org/10.1073/pnas.93.15.7623

Matsuzaki Y, Ogawa-Ohnishi M, Mori A, Matsubayashi Y (2010) Secreted peptide signals required for maintenance of root stem cell niche in Arabidopsis. Science 329(5995):1065-1067. https://doi.org/10.1126/science.1191132

McGurl B, Pearce G, Orozco-Cardenas M, Ryan CA (1992) Structure, expression, and antisense inhibition of the systemin precursor gene. Science 255(5051): 1570-1573. https://doi.org/10.1126/science.1549783

Mosher S, Seybold H, Rodriguez P, Stahl M, Davies KA, Dayaratne S, Morillo SA, Wierzba M, Favery B, Keller H, Tax FE, Kemmerling B (2013) The tyrosinesulfated peptide receptors PSKR1 and PSY1R modify the immunity of Arabidopsis to biotrophic and necrotrophic pathogens in an antagonistic manner. Plant J 73(3):469-482. https://doi.org/10.1111/tpj.12050

Narvaez-Vasquez J, Pearce G, Ryan CA (2005) The plant cell wall matrix harbors a precursor of defense signaling peptides. Proc Natl Acad Sci U S A 102(36): 12974-12977. https://doi.org/10.1073/pnas.0505248102

Ngou BPM, Ahn HK, Ding P, Jones JDG (2021) Mutual potentiation of plant immunity by cell-surface and intracellular receptors. Nature 592(7852):110115. https://doi.org/10.1038/s41586-021-03315-7

Olsson V, Joos L, Zhu S, Gevaert K, Butenko MA, De Smet I (2019) Look closely, the beautiful may be small: precursor-derived peptides in plants. Annu Rev Plant Biol 70(1):153-186. https://doi.org/10.1146/annurev-arplant-042817-040413

Ou Y, Lu X, Zi Q, Xun Q, Zhang J, Wu Y, Shi H, Wei Z, Zhao B, Zhang X, He K, Gou X, Li C, Li J (2016) RGF1 INSENSTTIVE 1 to 5, a group of LRR receptor-like kinases, are essential for the perception of root meristem growth factor 1 in Arabidopsis thaliana. Cell Res 26(6):686-698. https://doi.org/10.1038/cr.2016.63

Patharkar OR, Walker JC (2016) Core mechanisms regulating developmentally timed and environmentally triggered abscission. Plant Physiol 172(1):510520. https://doi.org/10.1104/pp.16.01004

Pearce G, Moura DS, Stratmann J, Ryan CA (2001a) Production of multiple plant hormones from a single polyprotein precursor. Nature 411(6839):817-820. https://doi.org/10.1038/35081107

Pearce G, Moura DS, Stratmann J, Ryan CA Jr (2001 b) RALF, a 5-kDa ubiquitous polypeptide in plants, arrests root growth and development. Proc Natl Acad Sci U S A 98(22):12843-12847. https://doi.org/10.1073/pnas.201416998 
Pearce G, Strydom D, Johnson S, Ryan CA (1991) A polypeptide from tomato leaves induces wound-inducible proteinase inhibitor proteins. Science 253(5022):895-897. https://doi.org/10.1126/science.253.5022.895

Pearce G, Ryan CA (2003) Systemic signaling in tomato plants for defense against herbivores: isolation and characterization of three novel defense-signaling glycopeptide hormones coded in a single precursor gene. J Biol Chem 278(32):30044-30050. https://doi.org/10.1074/jbc.M304159200

Poncini L, Wyrsch I, Denervaud Tendon V, Vorley T, Boller T, Geldner N, Metraux JP, Lehmann S (2017) In roots of Arabidopsis thaliana, the damage-associated molecular pattern AtPep1 is a stronger elicitor of immune signalling than flg22 or the chitin heptamer. PLoS One 12(10):e0185808. https://doi.org/10.13 71/journal.pone.0185808

Poretsky E, Dressano K, Weckwerth P, Ruiz M, Char SN, Shi D, Abagyan R, Yang B, Huffaker A (2020) Differential activities of maize plant elicitor peptides as mediators of immune signaling and herbivore resistance. Plant J 104(6): 1582-1602. https://doi.org/10.1111/tpj.15022

Pruitt RN, Joe A, Zhang W, Feng W, Stewart V, Schwessinger B, Dinneny JR, Ronald PC (2017) A microbially derived tyrosine-sulfated peptide mimics a plant peptide hormone. New Phytol 215(2):725-736. https://doi.org/10.1111/ nph. 14609

Pruitt RN, Schwessinger B, Joe A, Thomas N, Liu F, Albert M, Robinson MR, Chan $\mathrm{LJ}$, Luu DD, Chen $\mathrm{H}$ et al (2015) The rice immune receptor XA21 recognizes a tyrosine-sulfated protein from a gram-negative bacterium. Sci Adv 1(6): e1500245. https://doi.org/10.1126/sciadv.1500245

Ranf S, Eschen-Lippold L, Pecher P, Lee J, Scheel D (2011) Interplay between calcium signalling and early signalling elements during defence responses to microbe- or damage-associated molecular patterns. Plant J 68(1):100-113. https://doi.org/10.1111/j.1365-313X.2011.04671.X

Reichardt S, Piepho HP, Stintzi A, Schaller A (2020) Peptide signaling for droughtinduced tomato flower drop. Science 367(6485):1482-1485. https://doi.org/1 $0.1126 /$ science.aaz5641

Rhodes J, Yang H, Moussu S, Boutrot F, Santiago J, Zipfel C (2021) Perception of a divergent family of phytocytokines by the Arabidopsis receptor kinase MIK2. Nat Commun 12(1):705. https://doi.org/10.1038/s41467-021-20932-y

Rich-Griffin C, Eichmann R, Reitz MU, Hermann S, Woolley-Allen K, Brown PE, Wiwatdirekkul K, Esteban E, Pasha A, Kogel KH, Provart NJ, Ott S, Schäfer P (2020) Regulation of cell type-specific immunity networks in Arabidopsis roots. Plant Cell 32(9):2742-2762. https://doi.org/10.1105/tpc.20.00154

Rodiuc N, Barlet X, Hok S, Perfus-Barbeoch L, Allasia V, Engler G, Séassau A, Marteu N, de Almeida-Engler J, Panabières F, Abad P, Kemmerling B, Marco Y, Favery B, Keller H (2016) Evolutionarily distant pathogens require the Arabidopsis phytosulfokine signalling pathway to establish disease. Plant Cell Environ 39(7):1396-1407 https://doi.org/10.1111/pce.12627

Ronald P, Joe A (2018) Molecular mimicry modulates plant host responses to pathogens. Ann Bot 121(1):17-23. https://doi.org/10.1093/aob/mcx125

Ross A, Yamada K, Hiruma K, Yamashita-Yamada M, Lu X, Takano Y, Tsuda K, Saijo Y (2014) The Arabidopsis PEPR pathway couples local and systemic plant immunity. EMBO J 33(1):62-75. https://doi.org/10.1002/embj.201284303

Ryan CA, Pearce G (2003) Systemins: a functionally defined family of peptide signals that regulate defensive genes in Solanaceae species. Proc Natl Acad Sci U S A 100(Suppl 2):14577-14580. https://doi.org/10.1073/pnas.19347881 00

Santiago J, Brandt B, Wildhagen M, Hohmann U, Hothorn LA, Butenko MA, Hothorn M (2016) Mechanistic insight into a peptide hormone signaling complex mediating floral organ abscission. Elife 5:e15075. https://doi.org/10. 7554/eLife.15075

Sauter M (2015) Phytosulfokine peptide signalling. J Exp Bot 66(17):5161-5169. https://doi.org/10.1093/jxb/erv071

Schardon K, Hohl M, Graff L, Pfannstiel J, Schulze W, Stintzi A, Schaller A (2016) Precursor processing for plant peptide hormone maturation by subtilisin-like serine proteinases. Science 354(6319):1594-1597. https:/doi.org/10.1126/science.aai8550

Shen W, Liu J, Li JF (2019) Type-II metacaspases mediate the processing of plant elicitor peptides in Arabidopsis. Mol Plant 12(11):1524-1533. https://doi.org/1 0.1016/j.molp.2019.08.003

Shen Y, Diener AC (2013) Arabidopsis thaliana RESISTANCE TO FUSARIUM OXYSPORUM 2 implicates tyrosine-sulfated peptide signaling in susceptibility and resistance to root infection. PLoS Genet 9(5):e1003525. https://doi.org/1 0.1371/journal.pgen.1003525

Shiu SH, Bleecker AB (2001) Receptor-like kinases from Arabidopsis form a monophyletic gene family related to animal receptor kinases. Proc Natl Acad Sci U S A 98(19):10763-10768. https://doi.org/10.1073/pnas.181141598
Song WY, Wang GL, Chen LL, Kim HS, Pi LY, Holsten T, Gardner J, Wang B, Zhai WX, Zhu LH, Fauquet C, Ronald P (1995) A receptor kinase-like protein encoded by the rice disease resistance gene, Xa21. Science 270(5243):18041806. https://doi.org/10.1126/science.270.5243.1804

Srivastava R, Liu JX, Guo H, Yin Y, Howell SH (2009) Regulation and processing of a plant peptide hormone, AtRALF23, in Arabidopsis. Plant J 59(6):930-939. https://doi.org/10.1111/j.1365-313X.2009.03926.x

Srivastava R, Liu JX, Howell SH (2008) Proteolytic processing of a precursor protein for a growth-promoting peptide by a subtilisin serine protease in Arabidopsis. Plant J 56(2):219-227. https://doi.org/10.1111/j.1365-313X.2008. 03598.x

Stegmann M, Monaghan J, Smakowska-Luzan E, Rovenich H, Lehner A, Holton N, Belkhadir Y, Zipfel C (2017) The receptor kinase FER is a RALF-regulated scaffold controlling plant immune signaling. Science 355(6322):287-289. https://doi.org/10.1126/science.aal2541

Stegmann, M, Zecua-Ramirez, P, Ludwig, C, Lee, HS, Peterson, B, Nimchuk, ZL, Belkhadir Y, Hückelhoven, R (2021). RGI-GOLVEN signalling promotes FLS2 abundance to regulate plant immunity. bioRxiv preprint. https://doi.org/10.11 01/2021.01.29.428839

Stenvik GE, Tandstad NM, Guo Y, Shi CL, Kristiansen W, Holmgren A, Clark SE, Aalen RB, Butenko MA (2008) The EPIP peptide of INFLORESCENCE DEFICIENT IN ABSCISSION is sufficient to induce abscission in Arabidopsis through the receptor-like kinases HAESA and HAESA-LIKE2. Plant Cell 20(7):1805-1817. https://doi.org/10.1105/tpc.108.059139

Stuhrwohldt N, Buhler E, Sauter M, Schaller A (2021) Phytosulfokine (PSK) precursor processing by subtilase SBT3.8 and PSK signaling improve drought stress tolerance in Arabidopsis. J Exp Bot 72(9):3427-3440. https://doi.org/1 0.1093/jxb/erab017

Takahashi F, Hanada K, Kondo T, Shinozaki K (2019) Hormone-like peptides and small coding genes in plant stress signaling and development. Curr Opin Plant Biol 51:88-95. https://doi.org/10.1016/j.pbi.2019.05.011

Tanaka K, Heil M (2021) Damage-associated molecular patterns (DAMPs) in plant innate immunity: applying the danger model and evolutionary perspectives. Annu Rev Phytopathol 59(1):53-75. https://doi.org/10.1146/annurev-phyto082718-100146

Thynne E, Saur IML, Simbaqueba J, Ogilvie HA, Gonzalez-Cendales Y, Mead O, Taranto A, Catanzariti AM, McDonald MC, Schwessinger B, Jones DA, Rathjen JP, Solomon PS (2017) Fungal phytopathogens encode functional homologues of plant rapid alkalinization factor (RALF) peptides. Mol Plant Pathol 18(6):811-824. https://doi.org/10.1111/mpp.12444

Tintor N, Ross A, Kanehara K, Yamada K, Fan L, Kemmerling B, Nurnberger T, Tsuda K, Saijo Y (2013) Layered pattern receptor signaling via ethylene and endogenous elicitor peptides during Arabidopsis immunity to bacterial infection. Proc Natl Acad Sci U S A 110(15):6211-6216. https://doi.org/10.1 073/pnas.1216780110

Vie AK, Najafi J, Liu B, Winge P, Butenko MA, Hornslien KS, Kumpf R, Aalen RB, Bones AM, Brembu T (2015) The IDA/IDA-LIKE and PIP/PIP-LIKE gene families in Arabidopsis: phylogenetic relationship, expression patterns, and transcriptional effect of the PIPL3 peptide. J Exp Bot 66(17):5351-5365. https://doi.org/10.1093/jxb/erv285

Wang X, Lupardus P, Laporte SL, Garcia KC (2009) Structural biology of shared cytokine receptors. Annu Rev Immunol 27:29-60. https://doi.org/10.1146/a nnurev.immunol.24.021605.090616

Wang J, Li H, Han Z, Zhang H, Wang T, Lin G, Chang J, Yang W, Chai J (2015) Allosteric receptor activation by the plant peptide hormone phytosulfokine. Nature 525(7568):265-268. https://doi.org/10.1038/nature14858

Wang L, Einig E, Almeida-Trapp M, Albert M, Fliegmann J, Mithofer A, Kalbacher H, Felix G (2018) The systemin receptor SYR1 enhances resistance of tomato against herbivorous insects. Nat Plants 4(3):152-156. https://doi.org/10.1038/s41477-018-0106-0

Wang X, Hou S, Wu Q, Lin M, Acharya BR, Wu D, Zhang W (2017) IDL6-HAE/HSL2 impacts pectin degradation and resistance to Pseudomonas syringae pv tomato DC3000 in Arabidopsis leaves. Plant J 89(2):250-263. https://doi.org/1 $0.1111 /$ tpj. 13380

Wang X, Zhang N, Zhang L, He Y, Cai C, Zhou J, Li J, Meng X (2021) Perception of the pathogen-induced peptide RGF7 by the receptor-like kinases RGI4 and RGI5 triggers innate immunity in Arabidopsis thaliana. New Phytol 230(3): 1110-1125. https://doi.org/10.1111/nph.17197

Whitford R, Fernandez A, Tejos R, Perez AC, Kleine-Vehn J, Vanneste S, Drozdzecki A, Leitner J, Abas L, Aerts M et al (2012) GOLVEN secretory peptides regulate auxin carrier turnover during plant gravitropic responses. Dev Cell 22(3):678685. https://doi.org/10.1016/j.devcel.2012.02.002 
Wood AKM, Walker C, Lee WS, Urban M, Hammond-Kosack KE (2020) Functional evaluation of a homologue of plant rapid alkalinisation factor (RALF) peptides in Fusarium graminearum. Fungal Biol 124(9):753-765. https://doi. org/10.1016/j.funbio.2020.05.001

Xiao Y, Stegmann M, Han Z, DeFalco TA, Parys K, Xu L, Belkhadir Y, Zipfel C, Chai J (2019) Mechanisms of RALF peptide perception by a heterotypic receptor complex. Nature 572(7768):270-274. https://doi.org/10.1038/s41586-019-1409-7

Yamada K, Yamashita-Yamada M, Hirase T, Fujiwara T, Tsuda K, Hiruma K, Saijo Y (2016) Danger peptide receptor signaling in plants ensures basal immunity upon pathogen-induced depletion of BAK1. EMBO J 35(1):46-61. https://doi org/10.15252/embj.201591807

Yamaguchi Y, Barona G, Ryan CA, Pearce G (2011) GmPep914, an eight-amino acid peptide isolated from soybean leaves, activates defense-related genes. Plant Physiol 156(2):932-942. https://doi.org/10.1104/pp.111.173096

Yamaguchi Y, Huffaker A, Bryan AC, Tax FE, Ryan CA (2010) PEPR2 is a second receptor for the Pep1 and Pep2 peptides and contributes to defense responses in Arabidopsis. Plant Cell 22(2):508-522. https://doi.org/10.1105/tpc.109.068874

Yamaguchi Y, Pearce G, Ryan CA (2006) The cell surface leucine-rich repeat receptor for AtPep1, an endogenous peptide elicitor in Arabidopsis, is functional in transgenic tobacco cells. Proc Natl Acad Sci U S A 103(26): 10104-10109. https://doi.org/10.1073/pnas.0603729103

Yang H, Matsubayashi Y, Nakamura K, Sakagami Y (2001) Diversity of Arabidopsis genes encoding precursors for phytosulfokine, a peptide growth factor. Plant Physiol 127(3):842-851. https://doi.org/10.1104/pp.010452

Yu F, Qian L, Nibau C, Duan Q, Kita D, Levasseur K, Li X, Lu C, Li H, Hou C, Li L, Buchanan BB, Chen L, Cheung AY, Li D, Luan S (2012) FERONIA receptor kinase pathway suppresses abscisic acid signaling in Arabidopsis by activating ABI2 phosphatase. Proc Natl Acad Sci U S A 109(36):14693-14698, https://doi.org/10.1073/pnas.1212547109

Yu X, Feng B, He P, Shan L (2017) From chaos to harmony: responses and signaling upon microbial pattern recognition. Annu Rev Phytopathol 55(1): 109-137. https://doi.org/10.1146/annurev-phyto-080516-035649

Yu Z, Xu Y, Zhu L, Zhang L, Liu L, Zhang D, Li D, Wu C, Huang J, Yang G, Yan K, Zhang S, Zheng C (2020) The Brassicaceae-specific secreted peptides, STMPs, function in plant growth and pathogen defense. J Integr Plant Biol 62(4): 403-420. https://doi.org/10.1111/jipb.12817

Yuan M, Jiang Z, Bi G, Nomura K, Liu M, Wang Y, Cai B, Zhou JM, He SY, Xin XF (2021) Pattern-recognition receptors are required for NLR-mediated plant immunity. Nature 592(7852):105-109. https:/doi.org/10.1038/541586-021-03316-6

Zhang H, Hu Z, Lei C, Zheng C, Wang J, Shao S, Li X, Xia X, Cai X, Zhou J, Zhou Y, Yu J, Foyer CH, Shi K (2018) A plant phytosulfokine peptide initiates auxindependent immunity through cytosolic $\mathrm{Ca}(2+)$ signaling in tomato. Plant Cell 30(3):652-667. https://doi.org/10.1105/tpc.17.00537

Zhang H, Zhang H, Lin J (2020a) Systemin-mediated long-distance systemic defense responses. New Phytol 226(6):1573-1582. https://doi.org/10.1111/nph.16495

Zhang X, Peng H, Zhu S, Xing J, Li X, Zhu Z, Zheng J, Wang L, Wang B, Chen J, Ming Z, Yao K, Jian J, Luan S, Coleman-Derr D, Liao H, Peng Y, Peng D, Yu F (2020b) Nematode-encoded RALF peptide mimics facilitate parasitism of plants through the FERONIA receptor kinase. Mol Plant 13(10):1434-1454. https://doi.org/10.1016/j.molp.2020.08.014

Zhao C, Zayed O, Yu Z, Jiang W, Zhu P, Hsu CC, Zhang L, Tao WA, Lozano-Duran R, Zhu JK (2018) Leucine-rich repeat extensin proteins regulate plant salt tolerance in Arabidopsis. Proc Natl Acad Sci U S A 115(51):13123-13128. https://doi.org/10.1073/pnas.1816991115

Zhou JM, Zhang Y (2020) Plant immunity: danger perception and signaling. Cell 181(5):978-989. https://doi.org/10.1016/j.cell.2020.04.028

Zhu P, Yu XH, Wang C, Zhang Q, Liu W, McSweeney S, Shanklin J, Lam E, Liu Q (2020) Structural basis for $\mathrm{Ca}(2+)$ - dependent activation of a plant metacaspase. Nat Commun 11(1):2249. https://doi.org/10.1038/s41467-020-1 5830-8

Zhu S, Fu Q, Xu F, Zheng H, Yu F (2021) New paradigms in cell adaptation: decades of discoveries on the CrRLK1L receptor kinase signalling network. New Phytol. https://doi.org/10.1111/nph.17683

Ziemann S, van der Linde K, Lahrmann U, Acar B, Kaschani F, Colby T, Kaiser M, Ding Y, Schmelz E, Huffaker A, Holton N, Zipfel C, Doehlemann G (2018) An apoplastic peptide activates salicylic acid signalling in maize. Nat Plants 4(3): 172-180. https://doi.org/10.1038/s41477-018-0116-y

\section{Publisher's Note}

Springer Nature remains neutral with regard to jurisdictional claims in published maps and institutional affiliations. 